\title{
ASSESSMENT OF EXPOSURE TO FUNGI IN THE HEAVILY CONTAMINATED WORK ENVIRONMENT (A SOLID WASTE SORTING PLANT) BASED ON THE ERGOSTEROL ANALYSIS
}

\author{
ANNA KOZAJDA ${ }^{1}$, KAROLINA JEŻAK${ }^{1}$, MALGORZATA SOWIAK${ }^{1}$, BEATA GUTAROWSKA², \\ and IRENA SZADKOWSKA-STAŃCZYK ${ }^{1}$
}

${ }^{1}$ Nofer Institute of Occupational Medicine, Łódź, Poland

Department of Environmental Health Hazards

${ }^{2}$ Lodz University of Technology, Lódź, Poland

Biotechnology and Food Science Department, Institute of Fermentation Technology and Microbiology

\begin{abstract}
Objectives: This paper reports on the results of the study aimed at application of ergosterol as an quantitative indicator of fungal bioaerosol present in the indoor air in occupational environment heavily contaminated with organic dust as well as its comparison with the culturable method. Material and Methods: The study was conducted in the indoor solid waste sorting plant. Using Andersen impactor adapted to 1 plate at the flow rate of $30 \mathrm{l} / \mathrm{min}$, indoor air was sampled in the workers' breathing zone. Ergosterol was sampled using gelatinous filter (1000 l of air) and then analyzed by means of the spectrophotometric method. Fungi were sampled on malt extract agar (MEA) medium (3 replications: 21, 7.5 1, 151 of air) and analyzed by means of the culturable method. Based on ergosterol analyzes, concentration of fungi was calculated. Results were given as the range assuming min. as $5.1 \mathrm{pg}$ ergosterol/spore and max as $1.7 \mathrm{pg}$ ergosterol/spore. Results: The average concentrations of ergosterol in a working room (arithmetic mean (AM), standard deviation (SD); minimum-maximum (min.-max)) were, respectively: $2.16,0.72 ; 0.85-2.92 \mu \mathrm{g} / \mathrm{m}^{3}$; fungi calculated based on ergosterol $-424.1 \times 10^{3}-1272.4 \times 10^{3}, 140.1 \times 10^{3}-$ $420.4 \times 10^{3}, 167 \times 10^{3}-1716.5 \times 10^{3} \mathrm{CFU} / \mathrm{m}^{3}$, and culturable fungi $\left.-13 \times 10^{3}, 9.7 \times 10^{3}, 1.9 \times 10^{3}-34 \times 10^{3} \mathrm{CFU} / \mathrm{m}^{3}\right)$. It was revealed that concentrations of calculated fungi were even 2 orders of magnitude higher than culturable fungi. Conclusions: The quantitative assessment of moldiness by means of ergosterol measurement seems to be a reliable indicator for environments heavily contaminated with organic dust, where viable and non-viable fungi are present in high proportions. Based on that result, more restrictive (as compared to a similar assessment carried out by means of the culturable method) hygienic recommendations, especially those related to the use of preventive measures protecting the employees' respiratory tract, should have been undertaken.
\end{abstract}

Key words:

Occupational exposure, Bioaerosols, Sterols, Solid waste management plant, Ergosterol, Indoor air pollution

\footnotetext{
The project was financed with a grant for statutory activity of the Nofer Institute of Occupational Medicine, Lódź, Poland, from the subsidy No. IMP 3.5/2008 "Indicators of exposure to fungi (glucan, ergosterol) in the work environment of the municipal waste sorting plant." Project leader: Anna Kozajda, PhD.

Received: September 8, 2014. Accepted: January 8, 2015.

Corresponding author: A. Kozajda, Nofer Institute of Occupational Medicine, Department of Environmental Health Hazards, św. Teresy 8, 91-348 Łódź, Poland (e-mail: anias@imp.lodz.pl).
} 


\section{INTRODUCTION}

Assessment of fungal contamination in various environments, performed using the traditional culturable technique, is encumbered with a considerable error caused by methodological limitations. An important issue is that sampling and subsequent analytical process may strongly influence the quality of bioaerosol sample.

Therefore non-culturable methods are recommended for this purpose, including determination of ergosterol level as a suitable marker of fungal mass in air sample [1-3]. Ergosterol was usually determined using the high-performance liquid chromatography (HPLC), gas chromatography (GC), mass spectrometry (MS) and spectrophotometric techniques $[4,5]$.

Ergosterol is a lipid contained in cell membranes of all molds and yeasts. This molecular constituent of fungi and spores membranes may be used as an indicator of mycelium mass present in air samples or in raw material. Ergosterol is a highly specific compound for fungi but its slight amounts may contain algae and protozoa. It is a sterol found in the group of provitamins D; due to a characteristic spectrum within ultraviolet (UV) rays it differs from other sterols and their derivatives, which were used in methodology of its measurement. This compound starts to arise in mycelium at its early growth stage, it occurs in all phases of its development, and, which is significant, it is also present in spores. Furthermore, it is important that ergosterol, as long as it is not subjected to the sun's light, it is a very stable compound and occurs in both non-viable and viable mycelium, therefore it may be a good indicator of real moldiness [6].

There are both studies indicating a strong correlation between the concentrations of fungi and ergosterol, and research which did not show such a high correlation [7].

As ergosterol is specific to the fungi, in recent years some studies have been conducted on its use as an indicator of moldiness in various environments. The presence of ergosterol as an indicator of fungal mass growth is also a signal of a potential synthesis of mycotoxins, besides it may indirectly point to the presence of fungal allergens [8]. An additional advantage is a short duration of analysis (approx. $2 \mathrm{~h}$ ). This method has been used for years in studies on fungal contamination of products of vegetable origin [4]. In recent years, studies have been carried on to check its use for evaluation of building materials moldiness [7,9] and to evaluate microbiological indoor air quality $[1,3]$. Furthermore, in the past decade several studies were carried out to find a correlation between the concentration of ergosterol and the occurrence of health effects in exposed people. These studies were focused on agricultural and residential or office environment [10,11].

Miller and Young [1] demonstrated that the amount of ergosterol was connected with the number and size of fungal spores. Single average fungal spores belonging to the genera of Aspergillus, Cladosporium and Penicillium were found to contain 1.7-5.1 pg of ergosterol. Many studies have been published indicating the presence of very high concentrations of fungi in indoor air in the solid waste sorting plant environment [12-15]. It is also known that workers at this type of plants complain about many disease symptoms [16-20].

This study is aimed at assessment of the contamination of occupational environment (a municipal solid waste sorting plant) with fungi, using ergosterol as a quantitative indicator of the presence of fungi in air as well as its comparison with the culturable method. The presented study is the 1st attempt of applying this indicator in the environment heavily contaminated with fungi.

\section{MATERIAL AND METHODS}

The study was carried out in 2008 in the indoor solid waste sorting plant operative in an urban agglomeration (cubic capacity standing approx. at $80000 \mathrm{~m}^{3}$ ). The ventilation system for all seasons works at the same capacity but in the summer season 2 large gates are also open. Air sampling was carried out in the warmest period of 
the summer season $\left(25.8^{\circ} \mathrm{C}\right)$ because such climatic conditions favor the growth of microorganisms, and consequently the exposure to biological hazards in solid waste sorting plants is the highest.

Air samples were collected at the following points:

- the supply station 1 (the delivered solid waste unloading site),

- the supply station 2 (the working site of the loader scraping solid waste onto the belt),

- the supply station 3 (the workstation of an employee who manually gathers solid waste onto the belt),

- the sorting cabin 1 ,

- the sorting cabin 2,

- the sorting cabin 3,

- the transfer station 1 ,

- the transfer station 2 (the sorting belt),

- the press,

- the office room,

- the outdoor background - atmospheric air, direct neighborhood of the sorting plant area (distance approx. $200 \mathrm{~m}$ on the windward side) in the sunny and windy weather (mean air flow measured in 10 min stood at $0.85 \mathrm{~m} / \mathrm{s}$ ).

The 3 sorting cabins were located in a continuous line, one after another.

Temperature and relative humidity of air were measured using a multifunction microclimate meter Testo 435-2 (Testo AG, Lenzkirche, Germany) in the employees' breathing zone $1.5 \mathrm{~m}$ above the floor within $10 \mathrm{~min}$. The values of each of the measured parameters were read out every minute; subsequently the results were presented as the mean value for each measuring point.

To determine the concentrations of fungi and ergosterol, air samples were collected in a stationary way by means of the impaction technique, using a microbiological Andersen impactor (made by Westech Instrument Services Ltd, USA) adapted to 1 plate [21], using an appropriate medium (fungi) or gelatinous filter (ergosterol). Due to the fact that the same employees perform work in different places of the sorting house, the measuring points were selected so as to possibly perform measurements in the whole working area. Air samples were also taken in the office room situated in the same building and separated from the working premises by a space dividing element. Pursuant to recommendations of the Polish and European Standard PN-EN 13098 [22], all air samples were collected in the employees' breathing zone, i.e., at the level of approx. $1.5 \mathrm{~m}$ above the floor.

\section{Determination of ergosterol concentrations}

Eleven samples in 1 repetition were collected to analyze ergosterol, including 1 sample in the office room and additionally 1 outdoor air sample as the background. Air samples of 10001 volume were collected by means of the Andersen impactor adjusted to a single plate at the $30 \mathrm{l} / \mathrm{m}$ air flow. The air was collected on microbiological gelatinous filters with $3 \mu \mathrm{m}$ diameter of pores (Sartorius, Germany). Samples were transported in the mobile refrigerator directly to the laboratory where they were analyzed.

Filters with collected samples were dissolved in $20 \mathrm{ml}$ of sterile distilled water heated up to $25^{\circ} \mathrm{C}$. Eighty milliliters of methanol was added to aqueous solution and then sterols were extracted by shaking for $30 \mathrm{~min}$. Ten milliliters of 1-molar methanol solution of potassium hydroxide $(\mathrm{KOH})$ was added to methanol extract and then heated under reflux condenser for $30 \mathrm{~min}$. Having been cooled to the temperature of approx. $4^{\circ} \mathrm{C}$, the sample was extracted twice by hexane $(100 \mathrm{ml})$ for $2 \mathrm{~min}$.

The separated upper hexane fraction was evaporated to dryness on a vacuum evaporator. The dry residue was dissolved in $30 \mathrm{ml}$ of methanol and subjected to the UV spectrophotometric analysis at the $1=282.6 \mathrm{~nm}$ wavelength, using Beckman DU 640 in relation to the standard solution of methanol. The basic solution for standard curve (1 mg standard ergosterol (SigmaAldrich, Germany) in $1 \mathrm{ml}$ methanol) was diluted to obtain 
concentration: 5, 10, 20, 30, 40, 50, 100, 250, 500, $1000 \mu \mathrm{g}$ of ergosterol in $1 \mathrm{ml}$ methanol. The level of ergosterol was read out from the standard curve and then recalculated according to the formula:

$$
\mathrm{Y}=0.07296+36.90037 \times \mathrm{X}
$$

where:

$\mathrm{Y}$ - ergosterol concentration in the sample,

$\mathrm{X}$ - absorbance.

The calculated concentration was presented in terms of $\mu \mathrm{g} / \mathrm{m}^{3}$.

\section{Determination of fungi concentration}

\section{Theoretical method}

(based on ergosterol concentrations)

The published data indicates that 1 spore of the fungi of Aspergillus, Cladosporium and Penicillium genera may contain 1.7-5.1 pg of ergosterol [1]. In our study, the mentioned above genera of fungi were dominant and the results of the microbiological analysis (culturable and microscopic method based on morphological characteristics) are being prepared for publication. Applying this assumption and knowing ergosterol level, a concentration of airborne fungi at workstations was calculated. The results were presented in terms of $\mathrm{CFU} / \mathrm{m}^{3}$ as a minimal-maximal (min.max) range, the min. value meaning the assumption that 1 spore contained $5.1 \mathrm{pg}$ of ergosterol, whereas with max value it was assumed that 1 spore contained $1.7 \mathrm{pg}$ of ergosterol. The results are presented in terms of $\mathrm{CFU} / \mathrm{m}^{3}$ of air.

\section{Culturable method}

Similar to ergosterol sampling 11 samples were collected, including 1 in an office room, and additionally 1 as a background of the study. All samples were repeated 3 times by means of the impaction technique, using the Andersen impactor adjusted to one plate with the $30 \mathrm{l} / \mathrm{m}$ air flow on the malt extract agar (MEA) medium, with added chloramphenicol and streptomycin. In the working premises and office room the air of volumes 2, 7,5 and 151 was sampled whereas outdoor air was sampled in the volumes of 10, 20 and 401 . Various air volumes were sampled to obtain the growth of colonies in an amount which will enable microbiological analysis consistent with the colonies counting principles [23].

The samples were incubated for 5 days at $30^{\circ} \mathrm{C}$; subsequently the colonies were counted, and having included a statistical amendment the results were presented as $\mathrm{CFU} / \mathrm{m}^{3}$ of air.

\section{Data analysis}

Exposure to ergosterol and airborne fungi in the solid waste sorting plant environment was characterized using arithmetic means (AM), standard deviation (SD) and the range of the observed values. The correlation between the concentrations of ergosterol and fungi, determined by means of the culturable method, was analyzed by the linear regression method. Statistical inference was carried out with a significance level of 0.05 by 2 -sided tests. Statistical calculations were made using software Statistica 7.1 (prod. StatSoft, Poland).

\section{RESULTS}

The results of microclimatic parameters measurements in the solid waste sorting plant on the sampling day amounted, for temperature and relative humidity, respectively to: in the working room: $21.2^{\circ} \mathrm{C}$ and $56.8 \%$; in the office room: $23.7^{\circ} \mathrm{C}$ and $50.8 \%$; in the outdoor background: $25.8^{\circ} \mathrm{C}$ and $42 \%$.

The results of ergosterol level analysis, calculated concentrations of fungi and airborne concentrations of fungi measured by means of the culturable method at workplaces, in total and in respective sampling points in the studied solid waste sorting plant, are presented in the Table 1 . The mean concentration of ergosterol in working room amounted to $2.16 \mu \mathrm{g} / \mathrm{m}^{3}$, with the concentration 
Table 1. Concentrations of ergosterol and fungi calculated based on ergosterol and determined by means of the culturable method in the air in the solid waste sorting plant $(\mathrm{N}=11)$

\begin{tabular}{|c|c|c|c|c|c|}
\hline \multirow{3}{*}{$\begin{array}{l}\text { Air sampling } \\
\text { point } \\
\text { (No.) }\end{array}$} & \multirow{3}{*}{ Air sampling point } & \multirow{3}{*}{$\begin{array}{c}\text { Ergosterol } \\
{\left[\mu \mathrm{g} / \mathrm{m}^{3}\right]}\end{array}$} & \multicolumn{3}{|c|}{$\begin{array}{c}\text { Fungi } \\
{\left[\mathrm{CFU} / \mathrm{m}^{3} \times 10^{3}\right]}\end{array}$} \\
\hline & & & \multicolumn{2}{|c|}{ ergosterol } & \multirow{2}{*}{ culturable method } \\
\hline & & & $\min$. & $\max$ & \\
\hline 1 & supply station & 1.53 & 300.10 & 900.31 & 9.80 \\
\hline 2 & supply station & 0.85 & 166.97 & 500.92 & 19.00 \\
\hline 3 & supply station & 1.78 & 349.30 & 1047.91 & 9.37 \\
\hline 4 & sorting cabin & 2.92 & 572.15 & 1716.46 & 17.00 \\
\hline 5 & sorting cabin & 2.63 & 516.44 & 1549.32 & 1.90 \\
\hline 6 & sorting cabin & 2.86 & 560.58 & 1681.73 & 5.80 \\
\hline 7 & transfer station & 1.73 & 338.45 & 1015.35 & 5.00 \\
\hline 8 & transfer station & 2.58 & 505.59 & 1516.76 & 15.00 \\
\hline 9 & press & 2.59 & 507.76 & 1523.27 & 34.00 \\
\hline $1-9$ & $\begin{array}{l}\text { working room } \\
\text { total }(\mathrm{AM} \pm \mathrm{SD})\end{array}$ & $2.16 \pm 0.72$ & $424.15 \pm 140.15$ & $1272.45 \pm 420.44$ & $12.98 \pm 9.75$ \\
\hline 10 & office room & 2.62 & 513.55 & 1540.64 & 1.30 \\
\hline 11 & outdoor background & 0.51 & 99.68 & 299.05 & 0.12 \\
\hline
\end{tabular}

$\mathrm{AM}$ - arithmetic mean; SD - standard deviation; outdoor background - outdoor air; min. - the lower range of the concentration of fungi $(1$ spore $=5.1 \mathrm{pg}$ ergosterol $)$; max - the upper range of the concentration of fungi ( 1 spore $=1.7 \mathrm{pg}$ ergosterol).

range $0.85-2.92 \mu \mathrm{g} / \mathrm{m}^{3}$. The mean value was over 4 times higher than in the case of outdoor air $\left(0.51 \mu \mathrm{g} / \mathrm{m}^{3}\right)$.

The lowest concentration was found in the supply station during operations of the loader scraping solid waste onto the belt (the sampling point No. 2) whereas the highest one referred to the sorting cabin No. 1 where solid waste underwent preliminary sorting (the sampling point No. 4). The concentration of ergosterol in air samples in the solid waste sorting plant was demonstrated to be much higher than in the atmospheric air control sample. In 3 sampling points (No. 1, 3, 7) the content of ergosterol exceeded twice the level determined for outdoor air whereas in 6 sampling points (No. 4, 5, 6, 8, 9, 10) the level of ergosterol was as much as 5 times higher than in the case of outdoor air.

The analysis of fungi concentration obtained by means of the culturable method showed their mean concentration in the working room at the level of $1.30 \times 10^{4} \mathrm{CFU} / \mathrm{m}^{3}$ $\left(\mathrm{SD}=9.75 \times 10^{3}\right.$, range: $\left.1.9 \times 10^{3}-3.4 \times 10^{4} \mathrm{CFU} / \mathrm{m}^{3}\right)$. The highest concentration was shown at the press crushing the sorted solid waste (the sampling point No. 9), and the lowest - in the office room (the sampling point No. 10). The analysis of the data related to the concentration of fungi determined by means of the culturable method indicates that both the average concentration of fungi in the working room and the concentrations found in respective sampling points exceeded by 1 or 2 value orders $\left(10^{3}\right.$ and $\left.10^{4} \mathrm{CFU} / \mathrm{m}^{3}\right)$ the level of fungal contamination in outdoor air $\left(10^{2} \mathrm{CFU} / \mathrm{m}^{3}\right)$. In the office room the air contamination was lower than at workplaces of the solid waste sorting plant, and also exceeded the value shown for outdoor air.

The mean concentrations of ergosterol and fungi (obtained by means of the culturable method) in the working 
room of the solid waste sorting plant were significantly higher than the concentrations of these agents in the outdoor background ( $p=0.01$ and $p=0.05$, respectively). In the further part of the analysis the concentrations of fungi determined by means of the 2 analyzed methods were compared. Calculated, based on ergosterol concentrations, average concentrations of fungi in the working room ranged from $4.24 \times 10^{5}-1.27 \times 10^{6} \mathrm{CFU} / \mathrm{m}^{3}$. When comparing these values with fungi concentrations obtained by means of the culturable method, a difference of even 2 orders of magnitude (100 times more cells) was found. The results are presented in the Figure 1. It was demonstrated that in all air sampling points, including the office room and outdoor background, the concentration of fungi determined by means of the culturable method was much lower than the concentration indicated by method based on measurement of ergosterol concentration. A particularly high difference between these concentrations was found in the measuring points No. 10 and 11 (office room and atmospheric air).

The Figure 2 presents the results of estimated correlation between ergosterol concentration and fungi concentration determined by means of the culturable method, pointing to the lack of significant correlation between these variables.

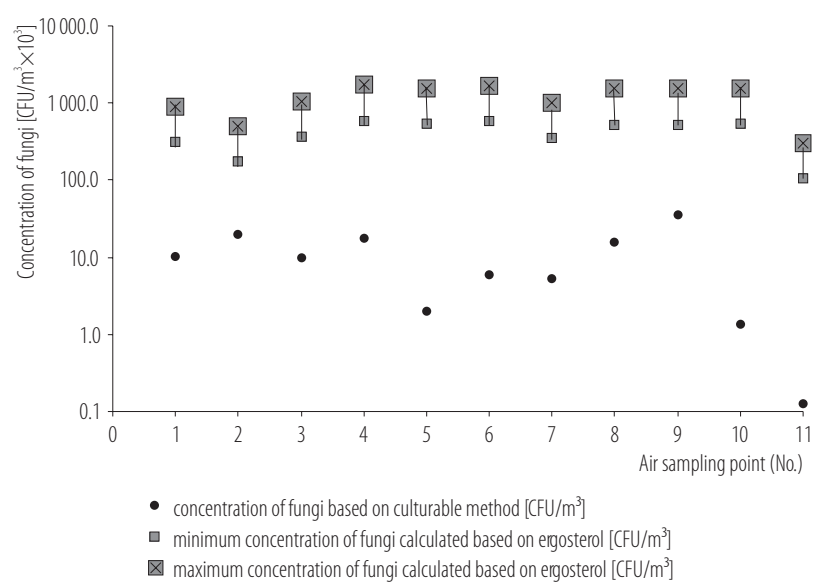

Fig. 1. Fungi concentration calculated according to ergosterol levels and determined by means of the culturable method in respective air samples collected in the solid waste sorting plant

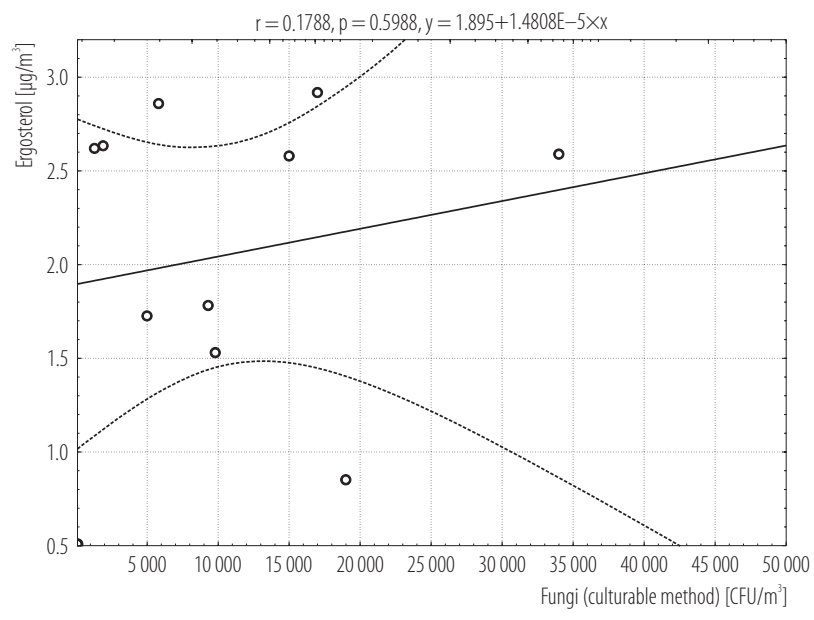

$r$ - correlation coefficient.

Statistical significance level: $\mathrm{p}<0.05$.

Fig. 2. Correlation of concentrations of ergosterol and fungi determined by means of the culturable method in all measuring points in the solid waste sorting plant

\section{DISCUSSION}

The fungi exposure indicator, i.e., measurement of ergosterol concentrations, was usually used to evaluate mold contamination of plants (storage and agricultural industry) and to evaluate fungal contamination of building materials. Based on these studies, several authors used the measurement of this sterol to evaluate indoor air fungal contamination $[1,3]$. In our study an attempt was made to use ergosterol concentrations as an indicator of the working environment air contamination with fungi.

The fungi levels calculated by us according to the obtained ergosterol concentrations were even by 2 orders of magnitude higher than those obtained by means of the culturable method. A similar relationship was shown by Robine et al. [3] in the study carried out in indoor air of apartments, schools, an office and laboratory. The authors obtained a calculated concentration of fungi, which was by 2-fold higher than the mean value obtained by means of the culturable method. This probably results from the fact that ergosterol is also an indicator of inactive fungal cells and, on the other hand its sampling method (in our study - sampling of 10001 of air) 
considerably decreases or perhaps even completely eliminates the measurement error accompanying the culturable method (underestimation of real concentration of microorganisms in connection with sampling of low air volumes and evaluation based exclusively on viable fungal cells).

Therefore we can assume that airborne ergosterol concentration indirectly points to real contamination by fungal aerosol (containing viable and nonviable cells, mainly spores). This was confirmed by arrangements made by Mille-Lindblom et al. [6], which indicate that ergosterol is a good indicator of the total fungal biomass because it is characterized by a relatively high stability in air after the cells' death, especially under the lack of solar exposure (UV radiation) which accelerates its degradation. The solid waste sorting plant studied by us was situated in a closed building, without an access of solar light, so we can assume that ergosterol contained in non-viable fungal cells was not decomposed fast after the cells' death.

The measurement of the concentration of all fungal cells present in air is extremely important due to arrangements made by Albrecht et al. [24], who according to the surveyed literature indicated that inactive or even dead cells of microorganisms could also induce adverse health effects in people. In Canada a study was carried out to try and use determination of airborne ergosterol concentration for evaluation of apartments microbiological purity [1]. The authors indicate it is a very good method of quantitative estimation of fungal biomass in indoor air, however, it is defective in that it is impossible to identify individual species of fungi. The indicator of fungi present in air, i.e., (1-3)- $\beta$-Dglucans, characterized by the same limitation, is still another one, often used in studies.

Foto et al. [8] found out that the differences confirmed between the concentrations of (1-3)- $\beta$-D-glucans and ergosterol as indicators of the presence of fungi in a specified environment result from the fact that in the case of glucans not only the substance of fungal origin is measured (also certain bacteria and many plants are a source of glucans [2]) whereas in the case of ergosterol it is a substance cumulated in viable and non-viable cells of fungi only. These authors in a study comparing the use of various methods of assessment of the indoor air fungal contamination, have indicated that the measurement of ergosterol is a more reliable indicator of the presence of fungi than glucans.

The concentrations of fungi which we measured were compared to the reference value recommended in Poland for working environment. This value for the total number of fungi in working rooms contaminated with organic dust amounts to $5 \times 10^{4} \mathrm{CFU} / \mathrm{m}^{3}$ of air [25]. Comparing it with the concentration of fungi determined by means of the culturable method, no excess was found but considering the concentration of fungi calculated based on airborne ergosterol concentration, the values much higher than the recommended normative were indicated.

It is worth mentioning that in our study apart from the working hall the air was also sampled in the office room situated in the same building and separated from the working premises only by the space dividing element. In the office room the concentration of ergosterol was higher than the mean value for the working hall, which probably resulted from the lack of complete isolation of this room from the solid waste storage and sorting sites, thereby facilitating the air circulation between these premises. Besides, this room was also available for solid waste sorting employees who entered them without taking off their working clothes.

The high concentration of ergosterol reported in the office room was also affected by that it was furnished with unclean upholstered chairs and armchairs which could have been covered with a thick coat of non-viable and viable microorganisms, including fungi, and by the upper shelves of furniture covered with seldom removed dust getting in from the working hall, which was floating because of an operating ventilator and air flow due to open windows.

In our study we found no statistically significant correlation between the concentration of ergosterol and viable fungi $(r=0.18, p>0.05)$. The low correlation surely 
results from the fact that in the air heavily contaminated with fungal bioaerosol, which is the case with the solid waste sorting plant's working environment, by using the volumetric-impaction culturable method the collected volume of air should be reduced so that the colonies developing on the Petri plate would not overgrow the substratum to the extent which would not allow for their analysis. This entails the need to sample a very low volume of air, which results in a considerable measurement error (underestimation, invalidated representativeness) which is absent during sampling of its higher volumes, e.g., in the microbiologically pure environment.

Fungi concentrations calculated according to ergosterol were by 2 orders of magnitude higher $\left(\max 10^{6} \mathrm{CFU} / \mathrm{m}^{3}\right)$, as compared to those found in the study made by means of the culturable method $\left(10^{4} \mathrm{CFU} / \mathrm{m}^{3}\right)$. These results confirm other authors' findings, according to which ergosterol analysis seems to be a more reliable method of quantitative assessment of real degree of contamination with fungal bioaerosol [1-3].

\section{CONCLUSIONS}

Although the number of measuring points was too low to issue binding general conclusions, however the obtained results point to existence of prerequisites for formulation of the following conclusions:

- Results of our study encourage to apply the ergosterol as the indicator of moldiness in the heavily contaminated environment.

- Assessment of the occupational environment, obtained by means of 2 methods, showed a different image of moldiness. The concentrations of fungi calculated according to ergosterol measurements at the solid waste sorting plant workplaces were by 2 orders of magnitude higher, as compared to those indicated by the culturable method.

- Estimation of moldiness carried out by ergosterol concentration would substantiate more restrictive hygienic recommendations, especially those related to the use of preventive measures protecting the employees' respiratory tract, as compared to the culturable method.

\section{REFERENCES}

1. Miller JD, Young CJ. The use of ergosterol to measure exposure to fungal propagules in indoor air. Am Ind Hyg Assoc J.1997;58:39-43, http://dx.doi.org/10.1080/15428119791013062.

2. Douwes J, Thorne P, Pearce N, Heederik D. Bioaerosol health effects and exposure assessment: Progress and prospects. Ann Occup Hyg. 2003;47:187-200, http://dx.doi.org/10.1093/ annhyg/meg032.

3. Robine ET, Lacaze I, Moularat S, Ritoux S, Boissier M. Characterisation of exposure to airborne fungi: Measurement of ergosterol. J Microbiol Methods. 2005;63:185-92, http://dx. doi.org/10.1016/j.mimet.2005.03.008.

4. Gessner M. Ergosterol as a measure of fungal biomass. In: Graça M, Bärlocher F, Gessner M, editors. Methods to study litter decomposition: A practical guide. Dordrecht: Springer; 2005. p. 189-96, http://dx.doi.org/10.1007/1-40203466-0_25.

5. Foto M, Vrijmoed L, Miller J, Ruest K, Lawton M, Dales R. A comparison of airborne ergosterol, glucan and Air-O-Cell data in relation to physical assessments of mold damage and some other parameters. Indoor Air. 2005;15:257-66, http:/ dx.doi.org/10.1111/j.1600-0668.2005.00370.x.

6. Mille-Lindblom C, von Wachenfeldt E, Tranvik LJ. Ergosterol as a measure of living fungal biomass: Persistence in environmental samples after fungal death. J Microbiol Methods. 2004;59(2):253-62, http://dx.doi.org/10.1016/j.mimet.2004.07.010.

7. Pasanen AL, Yli-Pietila K, Pasanen P, Kalliokoski P, Tarhanen J. Ergosterol content in various fungal species and biocontaminated building materials. Appl Environ Microbiol. 1999;65:138-42.

8. Saxena J, Munimbazi C, Bullerman LB. Relationship of mould count, ergosterol and ochratoxin A production. Int J Food Microbiol. 2001;71:29-34, http://dx.doi.org/10.1016/ S0168-1605(01)00584-0. 
9. Hippelein M, Rügamer M. Ergosterol as an indicator of mold growth on building materials. Int J Hyg Environ Health. 2004;207:379-85, http://dx.doi.org/10.1078/1438-4639-00303.

10. Dharmage S, Bailey M, Raven J, Abeyawickrama K, Cao D, Guest $\mathrm{D}$, et al. Mouldy houses influence symptoms of asthma among atopic individuals. Clin Exp Allergy. 2002;32(5):71420, http://dx.doi.org/10.1046/j.1365-2222.2002.01371.x.

11. Poole JA, Dooley GP, Saito R, Burrell AM, Bailey KL, Romberger DJ, et al. Muramic acid, endotoxin, 3-hydroxy fatty acids, and ergosterol content explain monocyte and epithelial cell inflammatory responses to agricultural dusts. J Toxicol Environ Health A. 2010;73(10):684-700, http://dx.doi. org/10.1080/15287390903578539.

12. Sigsgaard T, Hansen J, Malmros P. Biomonitoring and work related symptoms among garbage handling workers. Ann Agric Environ Med. 1997;4:107-12.

13. Wouters IM, Spaan A, Douwes J, Doekes G, Heederik D. Overview of personal occupational exposure levels to inhalable dust, endotoxin, $\beta(1 \rightarrow 3)$-glucan and fungal extracellular polysaccharides in the waste management chain. Ann Occup Hyg. 2006;50:39-53, http://dx.doi.org/10.1093/ annhyg/mei047.

14. Solans X, Alonso RM, Constans A, Mansilla A. [Occupational exposure to airborne fungi and bacteria in a household recycled container sorting plant]. Rev Iberoam Micol. 2007;24(2):131-5, http://dx.doi.org/10.1016/S1130-1406 (07)70028-1. Spanish.

15. Kozajda A, Sowiak M, Piotrowska M, Szadkowska-Stańczyk I. [Waste sorting plants - Recognition of exposure to biological agents (moulds)]. Med Pr. 2009;60(6):483-90. Polish.

16. Poulsen OM, Breum NO, Ebbehoj N, Hansen A, Ivens U, van Lelieveld $\mathrm{D}$, et al. Sorting and recycling of domestic waste. Review of occupational health problems and their possible causes. Sci Total Environ. 1995;168:33-56, http:// dx.doi.org/10.1016/0048-9697(95)04521-2.
17. Sigsgaard T. Health hazards to waste management workers in Denmark. Schriftenr Ver Wasser Boden Lufthyg. 1999;104:563-8.

18. Marth E, Reinthaler FF, Schaffler K, Jelovcan S, Haselbacher S, Eibel U, et al. Occupational health risks to employees of waste treatment facilities. Ann Agric Environ Med. 1997;4:143-7.

19. Wouters I, Hilhorst S, Kleppe P, Doekes G, Douwes J, Peretz C, et al. Upper airway inflammation and respiratory symptoms in domestic waste collectors. Occup Environ Med. 2002;59:106-12, http://dx.doi.org/10.1136/oem. 59.2.106.

20. Kozajda A, Szadkowska-Stańczyk I. [Selected health complains, allergic diseases, hygiene behaviors and knowledge of biohazards among workers of waste sorting plants]. Med Pr. 2009;60(6):491-9. Polish.

21. Jones W, Morring K, Morey P, Sorenson W. Evaluation of the Andersen viable impactor for single stage sampling. Am Ind Hyg Assoc J. 1985;46(5):294-8, http://dx.doi. org/10.1080/15298668591394833.

22. PN-EN 13098:2007. [The air in the workplace. Guidelines for the measurement of airborne microbial and endotoxins]. Warszawa: Polish Committee for Standardization; 2007. Polish.

23. PN-ISO 7954:1999. [Microbiology. General rules for determination of yeasts and molds. Plate method at 25 degrees C]. Warszawa: Polish Committee for Standardization; 1999. Polish.

24. Albrecht A, Witzenberger R, Bernzen U, Jäckel U. Detection of airborne microbes in a composting facility by cultivation based and cultivation-independent methods. Ann Agric Environ Med. 2007;14:81-5.

25. Górny R. [Biohazards: Standards, recommendations and proposals values]. Podst Metody Oceny Srod Pr. 2004;3 (41):17-39. Polish.

This work is available in Open Access model and licensed under a Creative Commons Attribution-NonCommercial 3.0 Poland License - http://creativecommons.org/ licenses/by-nc/3.0/pl/deed.en. 